\title{
Pile-Spacing Calculation of Anti-Slide Pile Based on Soil Arching Effect
}

\author{
Guangfu Chen, ${ }^{1,2}$ Liangchao Zou, ${ }^{3}$ Qing Wang $\mathbb{D}^{4}{ }^{4}$ and Guodong Zhang $\mathbb{D i D}^{1,2}$ \\ ${ }^{1}$ Key Laboratory of Geological Hazards on Three Gorges Reservoir Area (China Three Gorges University), Ministry of Education, \\ Yichang, Hubei Province, China \\ ${ }^{2}$ National Field Observation and Research Station of Landslides in Three Gorges Reservoir Area of Yangtze River, Yichang, \\ Hubei Province, China \\ ${ }^{3}$ Division of Energy, Resources and Infrastructure, Department of Sustainable Development, \\ Environmental Science and Engineering, KTH-Royal Institute of Technology, Stockholm, Sweden \\ ${ }^{4}$ Institute of Information Science and Technology, China Three Gorges University, Yichang, Hubei Province, China
}

Correspondence should be addressed to Qing Wang; wq@ctgu.edu.cn and Guodong Zhang; zgd@ctgu.edu.cn

Received 23 September 2019; Revised 30 April 2020; Accepted 1 May 2020; Published 23 May 2020

Academic Editor: Giovanni Biondi

Copyright (c) 2020 Guangfu Chen et al. This is an open access article distributed under the Creative Commons Attribution License, which permits unrestricted use, distribution, and reproduction in any medium, provided the original work is properly cited.

\begin{abstract}
Anti-slide pile is one of the most frequently used measures in landslide control globally. Pile-spacing has always been determined by the load capacity of single piles or according to engineering empirical experience. Many engineering practices and laboratory experiments show that the soil arching effect exists in landslide control with anti-slide piles. In this study, we aim to calculate pilespacing in terms of the soil arching effect. We investigated the pile-soil interaction mechanism and propose that, at the limit, the pile-back soil arch resists landslide thrust only. According to Mohr-Coulomb strength theory and limit equilibrium theories, we derived a new pile-spacing calculation equation. We verified the derived pile-spacing calculation equation with real projects. The calculated results are similar to those of practical engineering designs, in which the difference is within $10 \%$. The equation can be used in anti-slide pile preliminary design. This study can be a reference for pile-spacing calculation based on the soil arching effect.
\end{abstract}

\section{Introduction}

Many people worldwide suffer from serious destructions caused by landslides annually [1-4]. In landslide control, anti-slide piles are regarded as essential [5-7]. In anti-slide pile design, pile-spacing is a crucial parameter. If the pilespacing is designed to be excessively large, soil between the anti-slide piles will slip away; if the pile-spacing is designed to be excessively small, the investment would be high, and the construction process would be difficult.

In 1884, Roberts first discovered the granary effect, which is also known as the soil arching effect. In 1943, Terzaghi first investigated and defined the soil aching effect through a trap-door test. Subsequently, the soil arching effect was investigated comprehensively and further developed by many scholars. Atkinson and Potts [8], Li and Yang [9], and Huang et al. [10] studied the effect of soil arching on tunnel stability. Lee et al. [11] determined the boundaries of arching zones for both single and parallel tunneling. Bossecher and Gray [12] discovered that the soil arching effect occurred as soil attempted to move through the fixed piles in piled walls. Many engineering practices and laboratory experiments have shown that in landslide control with antislide piles, the soil arching effect occurred.

Pile-spacing is typically determined by a single pile's load capacity or engineering experience. In recent years, many studies have focused on the relationship between pilespacing and the soil arching effect, and researchers have attempted to calculate pile-spacing based on the soil arching effect. Sadrekarimi and Abbasnejad [13] discovered that pile clear spacing significantly affected the formation of a stable soil arch in a piled embankment. Yang et al. [14] discovered that for a certain embankment height, the soil arch height increased with the clear spacing of the pile cap within the 
range from 1 to $2 \mathrm{~m}$. Durrani et al. [15] proposed a limit on pile-spacing along a row where the arching of soil between adjacent piles was maintained during pile-soil movement. Such a limit would significantly affect the design of "discrete pile walls" used to prevent soil movement in potentially unstable slopes.

An effective measurement to detect soil arch form has not been developed yet. Pile-spacing calculation methods based on the soil arching effect have been established according to different hypotheses. Different hypotheses of soil arch form result in different pile-spacing calculation methods. We discovered that different pile-spacing calculation methods based on different hypotheses of soil arch form applied in the same project yielded different results and that some differences were large, e.g., the $\mathrm{Zi}$ Yang landslide that occurred on the north bank of Hanjiang, Hubei, China. Zhao et al. [16] considered an inclined soil arch and calculated the pile-spacing to be $7 \mathrm{~m}$. Jia et al. [17] proposed a pile-spacing calculation method based on assuming that soil arches between and behind piles function simultaneously; furthermore, the pile-spacing of the $\mathrm{Zi}$ Yang landslide was calculated to be $37.9 \mathrm{~m} \mathrm{[16]}$.

We comprehensively studied the pile-soil interaction mechanism. In this study, combining the analysis of practical engineering phenomena and laboratory experimental results, we established a soil arch force analysis model and derived a new pile-spacing calculation equation. We compared the results obtained by applying the equation to calculate the pile-spacing of slopes controlled using antislide piles. The calculated results were similar to those of practical engineering designs, in which the difference was within $10 \%$.

\section{Methodology}

2.1. Pile-Soil Interaction Process. The soil arching effect has been widely accepted in the pile-soil contact. During pilesoil interactions, soil arches behind and between piles generate, develop, and fracture. Different understanding regarding soil arches resulted in different pile-spacing calculation methods. The soil arches are shown in Figure 1.

The processes of soil arch generation, development, and fracture can be described as follows:

(1) The landslide thrust and relative displacement of soils between piles are small, and a local compressive zone is generated in the pile-back.

(2) As the landslide thrust increases, the local compressive zone of the pile-back enlarges, and the compressive deformation of soil increases accordingly. The soil between the piles generates a horizontal displacement relative to the piles. Because the friction effect exists between the pileside and the soil, a relative horizontal displacement will be hindered. Hence, a soil arch is generated between the pile-sides. The stability of the soil arch between the pile-sides relies on the frictional resistance generated between the soil and pile-side.

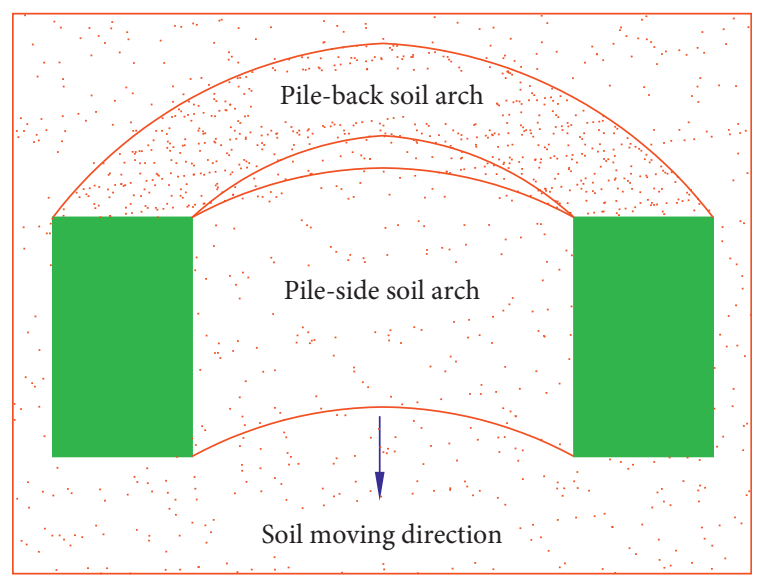

FIGURE 1: Soil arch plane graph.

(3) As the landslide thrust continues increasing, the displacement of soil between the pile-sides increases relative to the piles accordingly. Owing to the limited bearing capacity of the soil arch between the pilesides, during its displacement development, the pileback soil arch generates and resists the landslide thrust to compensate for the insufficient bearing capacity of the soil arch between the pile-sides.

(4) As the landslide thrust increases steadily, the density of soil within the soil arch between the pile-backs increases owing to compression, and the displacement of soil between the pile-sides increases relative to the pile accordingly. Owing to the small bearing capacity of the soil arch between the pile-sides, after a relatively large displacement, the soil arch between the pile-sides will generate fissures and hence breakage, and the soil arching effect of the soil arch between the pile-sides wears off or even disappears. For a cantilever pile, at this time, the soil between the pile-sides may begin to fall off.

(5) As the landslide thrust increases to the ultimate bearing capacity of the soil arch between the pilebacks, the deformation of soil within the soil arch foot area enlarges, fissures are generated, and the displacement of soil between the pile-sides continues to increase.

(6) Finally, as the landslide thrust increases, shear failure toward the pile-front will occur in the soil arch between the pile-backs. The soil surrounding the piles will be extruded, and the soil arching effect will fail.

Based on the soil arching effect introduced above, we conclude that the destruction of soil arches between pilebacks signifies the failure of landslide control using anti-slide piles. In other words, the soil arch between the pile-backs governs the soil arching effect in pile-soil interactions. This has been proven directly through laboratory tests and practical engineering phenomena. For example, the laboratory test, as illustrated in Figure 2(a), shows that the soil arch between the pile-sides was destroyed, whereas the pile- 


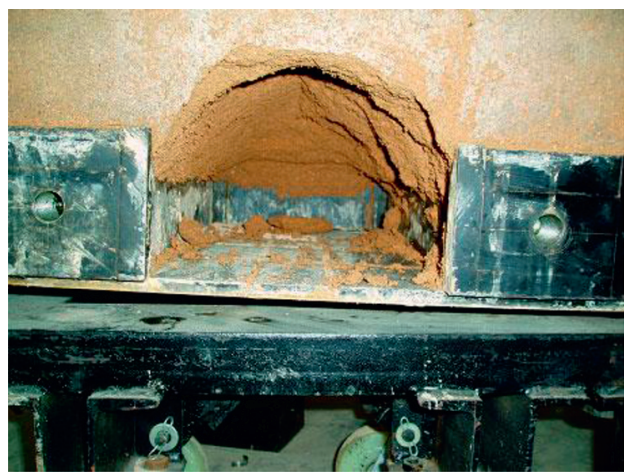

(a)

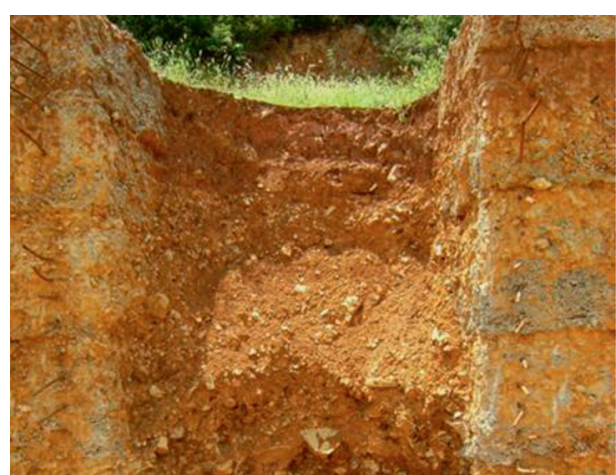

(b)

Figure 2: Pile-side soil arch destruction. (a) Laboratory test. (b) Practical engineering.

back soil remained steady [18]; the same was observed in practical engineering, as illustrated in Figure 2(b) [19].

According to the analysis above, we propose pile-back soil arch ultimate force analysis. Based on the latter, we derived the following pile-spacing calculation equation.

2.2. Pile-Back Soil Arch Form. Soil arch generation can be explained as follows: in a soil under an external force, a nonuniform displacement is produced, the soil adjusts the shear strength to resist the external force, and then a soil arch is generated. Soil arch generation is resulted from an optimized adjustment under an external force. Hence, the soil arch can develop a high bearing capacity. Additionally, neither shear force nor bending moment existed in the soil arch, only axial force.

To simplify the soil arch mode, we formed the following hypotheses [20-22]:

(1) The pile-back soil arch form is a reasonable arch axis curve, and a reasonable arch axis curve is a parabola.

(2) The landslide thrust is equally distributed between the anti-slide piles.

(3) The pile-back soil arch covers the entire back of the anti-slide piles.

(4) The soil arch self-gravity and sliding resistance are neglected.

The soil arch plane graph is shown in Figure 3. The antislide pile cross section is a rectangle, the soil arch rise is $h$, and the soil arch span is $2 l$.

According to the introduction above, the soil arch curve passes three points: $\mathrm{A}(-l, 0), \mathrm{B}(l, 0)$, and $\mathrm{C}(0, h)$. The soil arch curve is expressed as

$$
y=-\frac{h}{l^{2}} x^{2}+h
$$

2.3. Pile-Spacing Calculation. After analyzing the pile-soil interaction and the soil arch geometrical characteristics, we calculate the pile-spacing. Considering the complexity of the soil arching effect and to aim for a concise calculation process, we formed the following hypotheses:
(1) Only the pile-back soil arch is considered, i.e., the pile-side soil arch is neglected.

(2) The soil arch distributes equally along the anti-slide pile length, and no changes in form occur.

(3) Pile-soil friction is much larger than soil-soil friction; therefore, the soil arch will not break along the pilesoil contact face.

Considering the symmetry characteristic of the soil arch, we selected the left part for analysis, as shown in Figure 4. For any point $\mathrm{K}\left(F_{x}, F_{y}\right)$ in the soil arch curve, $F_{x}$ is the soil arch axial force horizontal component, $F_{y}$ is the soil arch axial force vertical component, and $F$ is the soil arch axial force. At the soil arch foot, $F_{x}^{\prime}$ is the arch foot horizontal component, $F_{y}^{\prime}$ is the arch foot vertical component, and $F^{\prime}$ is the arch foot axial force. $N$ is the axial compressive force of midspan section.

Based on equilibrium conditions, the forces can be calculated as follows:

$$
\begin{gathered}
F_{x}=\frac{q l^{2}}{2 h}, \\
F_{y}=q|x| .
\end{gathered}
$$

Therefore, the soil arch axial force $F$ of point $\mathrm{K}$ is expressed as follows:

$$
F=\sqrt{F_{x}^{2}+F_{y}^{2}}=\frac{q}{2 h} \sqrt{l^{4}+4 h^{2} x^{2}} .
$$

Equation (4) shows that the soil arch axial force increases with the distance from point $\mathrm{K}$ to the $y$-axis. Therefore, in the arch foot section, the largest axial force appeared. In other words, the arch foot section is the most susceptible to damage. Furthermore, we will not consider the control section of the midspan in the following limit analysis.

At the soil arch foot site, the forces can be calculated similarly as equations (2)-(4), as follows:

$$
\begin{gathered}
F_{x}^{\prime}=\frac{q l^{2}}{2 h}, \\
F_{y}^{\prime}=q l,
\end{gathered}
$$




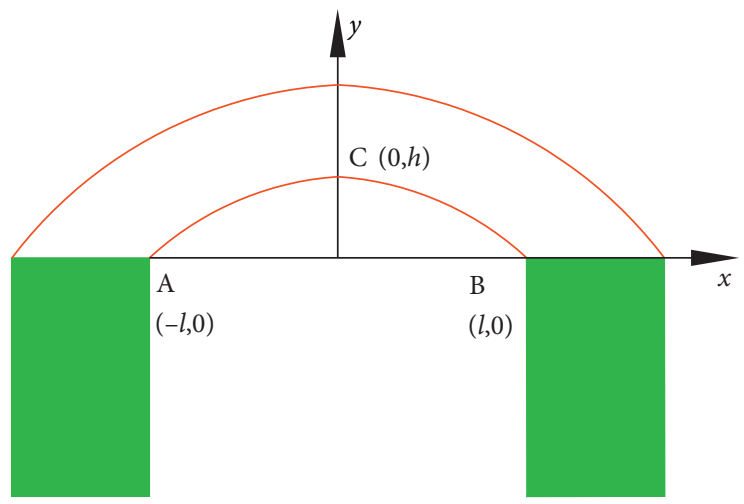

Figure 3: Soil arch plane graph for calculation.

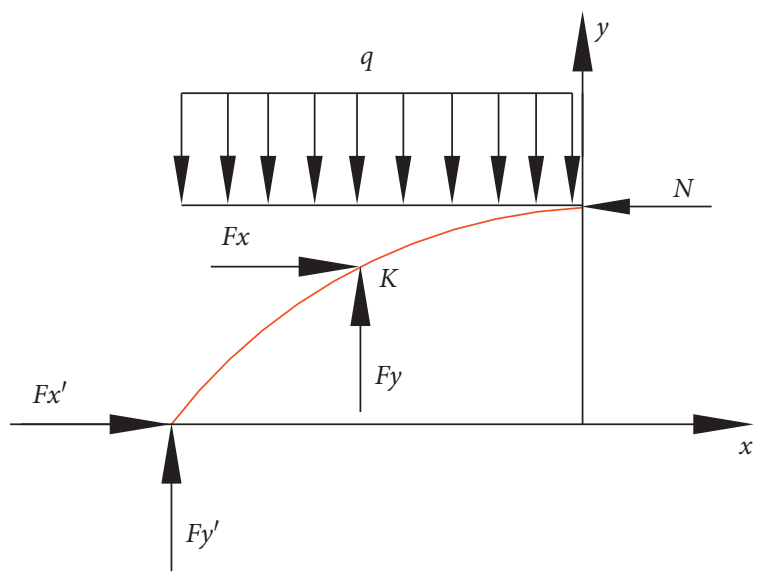

FIgURE 4: Simplified arch axis force analysis.

$$
F^{\prime}=\sqrt{F_{x}^{\prime 2}+F_{y}^{\prime 2}}=\frac{q l}{2 h} \sqrt{l^{2}+4 h^{2}} .
$$

Figure 5 shows the pile-back soil arch force, where $\triangle \mathrm{ADE}$ is the arch foot compressive zone, $\mathrm{AE}$ is the arch foot section, and $a$ is the pile-back width.

According to limit equilibrium theory, the angle between the major principal stress-acting face and fracture face is $45^{\circ}+(\varphi / 2)$. Therefore, at point $\mathrm{A}(-l, 0)$, the soil arch curve starting point, i.e., its tangent slope, is

$$
\tan \beta=\tan \left(45^{\circ}+\frac{\varphi}{2}\right)=\frac{F_{y}^{\prime}}{F_{x}^{\prime}}=\frac{2 h}{l} .
$$

For the soil arch, the arch foot section is the most susceptible to damage. According to the Mohr-Coulomb rule of uniaxial compression, the following equation can be obtained:

$$
\frac{F^{\prime}}{t}=2 c \tan \left(45^{\circ}+\frac{\varphi}{2}\right)
$$

where $t$ is the soil arch thickness, which can be calculated using trigonometric functions, as follows:

$$
t=\frac{a / 2}{\cos \left(45^{\circ}-(\varphi / 2)\right)}=\frac{a}{2 \cos \left(45^{\circ}-(\varphi / 2)\right)} .
$$

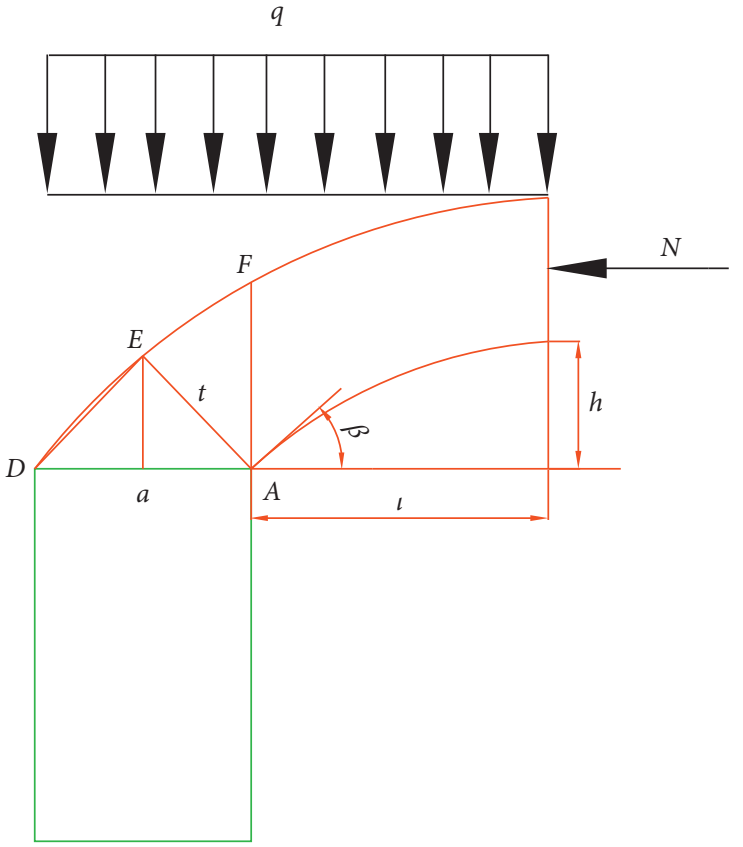

FIgURE 5: Pile-back soil arch force analysis.

Substituting equations (7) and (10) into equation (9) yields

$$
\frac{q l}{a h} \sqrt{l^{2}+4 h^{2}} \cos \left(45^{\circ}-\frac{\varphi}{2}\right)=2 c \tan \left(45^{\circ}+\frac{\varphi}{2}\right) .
$$

Finally, substituting equation (8) into equation (11) yields

$$
l=\frac{a c}{q} \frac{\tan ^{2}\left(45^{\circ}+(\varphi / 2)\right)}{\cos \left(45^{\circ}-(\varphi / 2)\right) \sqrt{1+\tan ^{2}\left(45^{\circ}+(\varphi / 2)\right)}} .
$$

Therefore, the pile-spacing $L$ can be expressed as

$$
L=\frac{2 a c}{q} \frac{\tan ^{2}\left(45^{\circ}+(\varphi / 2)\right)}{\cos \left(45^{\circ}-(\varphi / 2)\right) \sqrt{1+\tan ^{2}\left(45^{\circ}+(\varphi / 2)\right)}}+a .
$$




\section{Illustration Results}

To verify the proposed pile-spacing calculation method effect, we investigated practical projects controlled using anti-slide piles to perform a comparison.

3.1. Case 1. Piles were used to stabilize an 8-m-high railway embankment of weald clay at Hildenborough, Kent, UK [23]. Bored concrete piles measuring $0.6 \mathrm{~m}$ in diameter were constructed at a spacing of $2.4 \mathrm{~m}$. The cohesion and friction angle of the weald clay embankment fill were $20.9 \mathrm{kPa}$ and $25^{\circ}$, respectively [24]. Smethurst and Powrie [23] estimated the soil driving (shear) force required to achieve the desired safety factor and transferred by the pile to be $60 \mathrm{kN}$. The critical failure surface passed through the proposed pile location at a depth of $4 \mathrm{~m}$ below the slope surface.

As the pile was round, we first transformed it to a rectangle, of which the width is

$$
a=\sqrt{2} \times \frac{0.6}{2}=0.42 \mathrm{~m} .
$$

According to equation (13), the pile-spacing can be obtained as follows:

$$
\begin{aligned}
L= & \frac{2 \times 0.42 \times 20.9}{(60 / 4)} \frac{\tan ^{2}\left(45^{\circ}+\left(25^{\circ} / 2\right)\right)}{\cos \left(45^{\circ}-\left(25^{\circ} / 2\right)\right) \sqrt{1+\tan ^{2}\left(45^{\circ}+\left(25^{\circ} / 2\right)\right)}} \\
& +0.42=2.3 \mathrm{~m} .
\end{aligned}
$$

The calculated pile-spacing was $2.3 \mathrm{~m}$, which was smaller than that of the actual project, i.e., $2.4 \mathrm{~m}$. Smethurst and Powrie [23] reported that the actual restoring force must ensure that the stability of the slope is smaller than the estimated value; therefore, if the actual restoring force is adopted, the calculated pile-spacing will be larger than $2.3 \mathrm{~m}$, which is approximately or larger than the actual project.

3.2. Case 2. A highway cut slope located in north Sichuan, China, adopted cantilever piles for control. The soil cohesion and friction angle behind the pile were $50 \mathrm{kPa}$ and $28^{\circ}$, respectively. The pile cross section width was $2 \mathrm{~m}$, the length of the entire pile was $22 \mathrm{~m}$, and the cantilever measured $11 \mathrm{~m}$. The calculated unit width landslide thrust was $1050 \mathrm{kN} / \mathrm{m}$ [25].

Substituting the project parameters introduced above into equation (13), we obtain

$$
\begin{aligned}
L= & \frac{2 \times 2 \times 50}{(1050 / 11)} \frac{\tan ^{2}\left(45^{\circ}+\left(28^{\circ} / 2\right)\right)}{\cos \left(45^{\circ}-\left(28^{\circ} / 2\right)\right) \sqrt{1+\tan ^{2}\left(45^{\circ}+\left(28^{\circ} / 2\right)\right)}} \\
& +2=5.5 \mathrm{~m} .
\end{aligned}
$$

The calculated pile-spacing was $5.5 \mathrm{~m}$. The actual pilespacing was $6 \mathrm{~m}$; the slope remained steady since the completion of the project. Therefore, it is indirectly proven that the calculation equation is reasonable.

\section{Discussion and Conclusion}

Based on the assumption that the pile-back soil arch resists only the landslide thrust at the limit, we derived an equation to calculate the pile-spacing. The equation expresses the relationship among the pile-spacing, pile-back soil shear strength parameters, pile cross section, and landslide thrust. The pile-spacing increased accompanied with increased soil cohesion and friction angle; however, it decreased with increasing landslide thrust. For the calculation based on the hypothesis that the soil arch covers the entire pile-back, which aims to simplify the relationship between the pile cross section width and the soil arch thickness, the pile cross section is regarded as a definite value to some extent. In fact, the soil arch may not cover the entire pile-back if the pile cross section width continues increasing; therefore, this aspect must be investigated further.

The case studies showed that the calculated values were smaller than those from engineering practices. This may be attributed to the following reasons. First, the calculation method was based on the soil arching effect, but the landslide thrust adopted in the equation was still calculated to the pilesite, when it should be calculated to the arch rise. Therefore, the landslide thrust will be smaller, and according to the equation, the pile-spacing will be larger. Furthermore, the equation derived was based on the plane soil arching effect; as the sliding surface had an angle of inclination at the pilesite, the force on the soil arch should be the horizontal component of the landslide thrust. In the case studies, parameters related to the tilt angle were not considered; we directly adopted the landslide thrust instead, which might result in a smaller calculated pile-spacing.

The pile-spacing calculation equation derived is simple and direct. The calculated values were smaller than the values obtained from engineering practices within $10 \%$, thereby directly proving the steadiness and effectiveness of the calculation method.

\section{Conflicts of Interest}

The authors declare that they have no conflicts of interest.

\section{Acknowledgments}

This work was supported by the National Natural Science Foundation of China (grant no. 41807294) and the Open Fund of the Key Laboratory of Geological Hazards on Three Gorges Reservoir Area (China Three Gorges University), Ministry of Education (grant no. 2017KDZ05). The authors would like to thank Editage (http://www.editage.cn) for English language editing.

\section{References}

[1] J. S. Kargel, G. J. Leonard, D. H. Shugar et al., "Geomorphic and geologic controls of geohazards induced by Nepals 2015 Gorkha earthquake," Science, vol. 351, no. 6269, 2016. 
[2] L.-J. Su, K.-H. Hu, W.-F. Zhang et al., "Characteristics and triggering mechanism of Xinmo landslide on 24 June 2017 in Sichuan, China," Journal of Mountain Science, vol. 14, no. 9, pp. 1689-1700, 2017.

[3] S. Kannaujiya, S. L. Chattoraj, D. Jayalath et al., "Integration of satellite remote sensing and geophysical techniques (electrical resistivity tomography and ground penetrating radar) for landslide characterization at Kunjethi (Kalimath), Garhwal Himalaya, India," Natural Hazards, vol. 97, no. 3, pp. 1191-1208, 2019.

[4] T. Bong and Y. Son, "Probabilistic analysis of weathered soil slope in South Korea," Advances in Civil Engineering, vol. 2018, Article ID 2120854, 12 pages, 2018.

[5] R. Y. Liang, A. E. Joorabchi, and L. Li, "Analysis and design method for slope stabilization using a row of drilled shafts," Journal of Geotechnical and Geoenvironmental Engineering, vol. 140, no. 5, Article ID 04014001, 2014.

[6] G. Zhang and L. Wang, "Integrated analysis of a coupled mechanism for the failure processes of pile-reinforced slopes," Acta Geotechnica, vol. 11, no. 4, pp. 941-952, 2016.

[7] G. Zhang, L. Wang, and Y. Wang, "Pile reinforcement mechanism of soil slopes," Acta Geotechnica, vol. 12, no. 5, pp. 1035-1046, 2017.

[8] J. H. Atkinson and D. M. Potts, "Stability of a shallow circular tunnel in cohesionless soil," Géotechnique, vol. 27, no. 2, pp. 203-215, 1977.

[9] T. Z. Li and X. L. Yang, "Stability of plane strain tunnel headings in soils with tensile strength cut-off," Tunnelling and Underground Space Technology, vol. 95, p. 103138, 2020.

[10] F. Huang, M. Zhang, F. Wang, T. Ling, and X. Yang, "The failure mechanism of surrounding rock around an existing shield tunnel induced by an adjacent excavation," Computers and Geotechnics, vol. 117, Article ID 103236, 2020.

[11] C. J. Lee, K. H. Chiang, and C. M. Kuo, "Ground movement and tunnel stability when tunneling in sandy ground," Journal of the Chinese Institute of Engineers, vol. 27, no. 7, pp. 10211032, 2004.

[12] P. J. Bosscher and D. H. Gray, "Soil arching in sandy slopes," Journal of Geotechnical Engineering, vol. 112, no. 6, pp. 626-645, 1986.

[13] J. Sadrekarimi and A. Abbasnejad, "Arching effect in fine sand due to base yielding," Canadian Geotechnical Journal, vol. 47, no. 3, pp. 366-374, 2010.

[14] T. Yang, Z. Lu, J. Ni, and G. Wang, "3D finite-element modelling of soil arch shape in a piled embankment," Proceedings of the Institution of Civil Engineers-Geotechnical Engineering, vol. 172, no. 3, pp. 255-262, 2019.

[15] J. K. Durrani, E. A. Ellis, and D. J. Reddish, "Numerical modelling of lateral pile-soil interaction for a row of piles in a frictional soil," Advances in Transportation Geotechnics, Taylor \& Francis, Abingdon, UK, pp. 291-298, 2008.

[16] M. H. Zhao, B. B. Liao, and S. S. Liu, "Calculation of anti-slide piles spacing based on soil arching effect," Rock and Soil Mechanics, vol. 31, no. 4, pp. 1211-1216, 2010, in Chinese.

[17] H. L. Jia, C. H. Wang, and J. H. Li, "Analysis of pile spacing between anti-sliding piles and retaining piles in accordance with soil arching effect," Journal of Engineering Geology, vol. 12, no. 1, pp. 98-103, 2004, in Chinese.

[18] Y. Liang, C. S. Jiang, Q. H. Li, F. Li, and X. Y. Zhao, “Analysis of stress mechanism of pile composite structure based on soil arch test," Chinese Journal of Rock Mechanics and Engineering, vol. 33, no. S2, pp. 3825-3828, 2014, in Chinese.

[19] J. Dong, Y. X. Zhang, S. G. Wu, and Y. Chen, "Study of stability of soil between adjacent cantilever piles in incised slope," Rock and Soil Mechanics, vol. 30, no. 12, pp. 3881-3888, 2009, in Chinese.

[20] S. Goel and N. R. Patra, "Effect of arching on active earth pressure for rigid retaining walls considering translation mode," International Journal of Geomechanics, vol. 8, no. 2, pp. 123-133, 2008.

[21] L. S. Liu and S. G. Wu, "Calculation of earth pressure on baffle of cantilever anti-slide piles based on soil arching effects," Yantu Gongcheng Xuebao/Chinese Journal of Geotechnical Engineering, vol. 37, no. 2, pp. 153-157, 2015, in Chinese.

[22] Z. Y. Qiu, T. C. Han, H. Q. Dou et al., "Analysis of spacing between anti-slide piles considering soil arch on lateral sides and back," Journal of Zhejiang University (Engineering Science), vol. 50, no. 3, pp. 559-565, 2016, in Chinese.

[23] J. A. Smethurst and W. Powrie, "Monitoring and analysis of the bending behaviour of discrete piles used to stabilise a railway embankment," Géotechnique, vol. 57, no. 8, pp. 663-677, 2007.

[24] M. Ashour and H. Ardalan, "Analysis of pile stabilized slopes based on soil-pile interaction," Computers and Geotechnics, vol. 39, pp. 85-97, 2012.

[25] S. G. Xiao and F. Q. Cheng, "Further discussion on calculation method of rational spacing between two adjacent cantilever piles for stabilizing slope," Rock and Soil Mechanics, vol. 36, no. 1, pp. 111-116, 2015, in Chinese. 